\title{
Risk Factors Association with Cochlear Dysfunction on the First Hearing Screening in the Neonatal Intensive Care Unit
}

\author{
Sri Hadzriati ${ }^{1}$, A. Dwi Bahagia Febriani ${ }^{2}$, Ema Alasiry $^{3}$, Dasril Daud ${ }^{4}$, Eka Savitri $^{5}$ \\ ${ }^{1}$ Senior resident, Neonatalogy Division, Department of Pediatrics, Medical Faculty, Hasanuddin University, Makassar, Indonesia \\ ${ }^{2}$ Consultant of Neonatalogy Division, Department of Pediatrics, Medical Faculty, Hasanuddin University, Makassar, Indonesia \\ ${ }^{3}$ Consultant of Neonatalogy Division, Department of Pediatrics, Medical Faculty, Hasanuddin University, Makassar, Indonesia \\ ${ }^{4}$ Consultant of Hematology \& Oncology Division, Department of Pediatrics, Medical Faculty, Hasanuddin University, Makassar, \\ Indonesia
}

${ }^{5}$ Consultant of TNT Department, Medical Faculty, Hasanuddin University, Makassar, Indonesia

\begin{abstract}
Background: Newborn who has been hospitalized in NICU is a group of high risk was recommended to screen for the possibility of hearing loss. The identification of cochlear dysfunction is a part of hearing screening that can be easily discovered by Otoacoustic Emission (OAE) examination. The aim of this study was to analyze some risk factors on the first hearing screening by $O A E$ exam and its probability for cochlear dysfunction. Materials and methods: This observational case control study was conducted from March until May 2015 in the Neonatal Intensive Care Unit (NICU) Dr. Wahidin Sudirohusodo Hospital Makassar. Detailed history and data including the gestational age, bilirubin level, Apgar Score, sepsis, and ototoxic drugs use were taken and analyzed using multivariate analyses and logistic regression model. Results: The results showed that $42.7 \%$ of the infants had cochlear dysfunction. Multivariate analyses revealed three risk factors associated with cochlear dysfunction: preterm with gestational age $\leq 32$ weeks (p=0.004, AOR 11.45; 95\%CI 2.13 to 61.51), hyperbilirubinemia with bilirubin level >20mg/dL ( $p=0.046$, AOR 10.28; 95\% CI 1.04 to 101.52) and asphyxia ( $p=0.006$, AOR 5.03; 95\% CI 1.59 to 15.89). Conclusion: The risk factors associated with cochlear dysfunction are preterm baby with gestational age $\leq 32$ weeks, hyperbilirubinemia with bilirubin level $>20 \mathrm{mg} / \mathrm{dL}$ and asphyxia.
\end{abstract}

Keywords: Cochlear Dysfunction, Hearing Impairment, NICU, OAE, Risk Factor

\section{Introduction}

Hearing plays an important role for children in learning speech and language, socialization and cognitive development. The child learns to speak based on what is heard so that child's hearing loss since birth will result in disturbance of speech, language, cognitive, social, and emotional. ${ }^{[1]}$ Hearing loss is different from that of other disability which in infants/ children with hearing loss often goes undetected or is not immediately known even by their own parents, this disorder is also known as "the invisible disability". The initial symptoms are difficult to know because deafness is not visible. Usually new parents are aware of hearing loss in children when there is no response to a loud noise or not/ too late to talk.

In Indonesia, the incidence of hearing loss or deafness from birth is not known yet. However, from the data obtained from the Health Survey senses of vision and hearing at 7 Province (1994-1996) with 19.375 respondents found $16.8 \%$ prevalence of hearing loss. All over the world there is approximately $0.1-0.3 \%$ of infants born deaf. ${ }^{[2]}$ US Preventive Services Task Force reported that the prevalence of neonatal hearing loss in the Neonatal Intensive Care Unit (NICU) is 10-20 times greater than the prevalence of hearing loss in a population of normal neonates. ${ }^{[3]}$

Hearing loss in newborns can be caused by various conditions. Risk factors include high levels of bilirubin, prematurity or low birth weight babies (LBW), ototoxic drugs, duration of mechanical ventilation, low Apgar score (asphyxia) and meningitis. ${ }^{[4]}$ Newborns with identified risk factors are recommended for the possibility of congenital and acquired hearing loss. ${ }^{[5]}$ Infants with the risk factors has the possibility of suffering from a hearing loss of 10.1 times compared with infants who do not have risk factors. ${ }^{[6]}$

The early identification of hearing loss and the appropriate intervention before 6 months of age is proven to prevent the consequences. The Joint Committee on Infant Hearing (JCIH) 2007 recommends neonatal hearing screening should be done. Research conducted by Nasrul, with has results of 66 samples examined showed OAE refer 8 cases $(12.1 \%)$, consisting of 6 cases refer unilateral $(6.1 \%)$ and 2 cases of bilateral refer $(3.0 \%)$, whereas pass cases are 58 samples $(87.9 \%){ }^{[7]}$ There are four risk factors, namely low birth weight, asphyxia, hyperbilirubinemia and premature. LBW most namely 14 cases $(21.2 \%)$ of the 66 samples. But the results refer three cases $(21.4 \%)$ of 14 cases of low birth weight. From this study it appears that the more risk factors the more likely the onset of deafness in newborns based on the results of OAE.

Risk factors for neonatal hearing loss (NHL) in the neonatal period by the JCIH are born preterm (gestational age $<34$ weeks), low birth weight ( $<1500 \mathrm{~g})$, a family history of deafness, congenital infections by Toxoplasmosis, Rubella, Cytomegalovirus and Herpes Simplex Virus (TORCH), 


\section{International Journal of Science and Research (IJSR) \\ ISSN (Online): 2319-7064 \\ Index Copernicus Value (2013): 6.14 | Impact Factor (2014): 5.611}

hyperbilirubinemia, craniofacial anomalies, syndromes associated with hearing impairment and severe asphyxia at birth (Apgar score $<7$ at 5 minutes) ${ }^{[5]}$ Another risk factor are the use of ototoxic drugs during pregnancy, a history of the use of a mechanical ventilator for more than 5 days, intraventricular hemorrhage, and high C-reactive protein (CRP) $(\geq 10 \mathrm{mg} / \mathrm{dl}){ }^{[8]}$

Hearing screening in newborns with risk factors had much to do, so that children who were diagnosed and had received his habilitation as early as possible indicate the language skills and better skills than children whose late diagnosis are. Cochlear dysfunction is the earliest abnormalities that can be detected in the screening of hearing loss. Based on the results of this cochlear dysfunction, the baby is re-screen at the age of 3 months to determine the diagnosis of hearing loss. In the cochlear dysfunction netting, we used Otoacustic Emissions (OAE) tool where it is easy to use in newborns, non-invasive, high sensitivity and can be used repeatedly. OAE weakness is the inability to detect abnormalities in nerve retrokoklea damage which are very vulnerable in newborns despite the relatively low prevalence of about $2.1 \%$ of deafness in children. Some studies showed that OAE has estimated sensitivity of $85-95 \%$ and a specificity of $90 \%$ or more. ${ }^{[9]}$ The purpose of this study was to assess the factors contribute to the occurrence of a cochlear dysfunction on the hearing screening in newborns who has been hospitalized in Neonatal Intensive Care Unit (NICU) using TOAE measurement.

\section{Materials and Methods}

An observational case-control study was conducted between March and May 2015. All the newborn hospitalized in the NICU of Dr. Wahidin Sudirohusodo Hospital who met the inclusion criteria were included in the study. The protocol was conducted in accordance with principles of good clinical practice, including obtaining written informed consent from each participant's parent, and was approved by the human studies committees applicable to each study site. The conditions of each newborn including the risk factors were noted: gestational age (New Ballard methods), birth weight, sex, family history of hearing loss; asphyxia (Apgar score 5 minute less than 7), sepsis, hyperbilirubinemia, and duration of ototoxic drugs used. Newborns that had craniofacial malformation or multiple congenital anomalies, and those with a family history of deafness were excluded from the study.

Ear examination carried out by using a light head and otoscope to assess the ear canal. If the ear canal is obtained a wax or blockage we then cleaning it (ear toilet). OAE examination carried out by using TEOAE, alternately in both ears. Examination carried out in a room that measured noise, $40 \mathrm{~dB}$ maximum. Baby lay on the bed or in the arms of the mother to ensure babies remain calm during the examination. OAE test results are recorded and grouped the results refer or pass then analyzed.

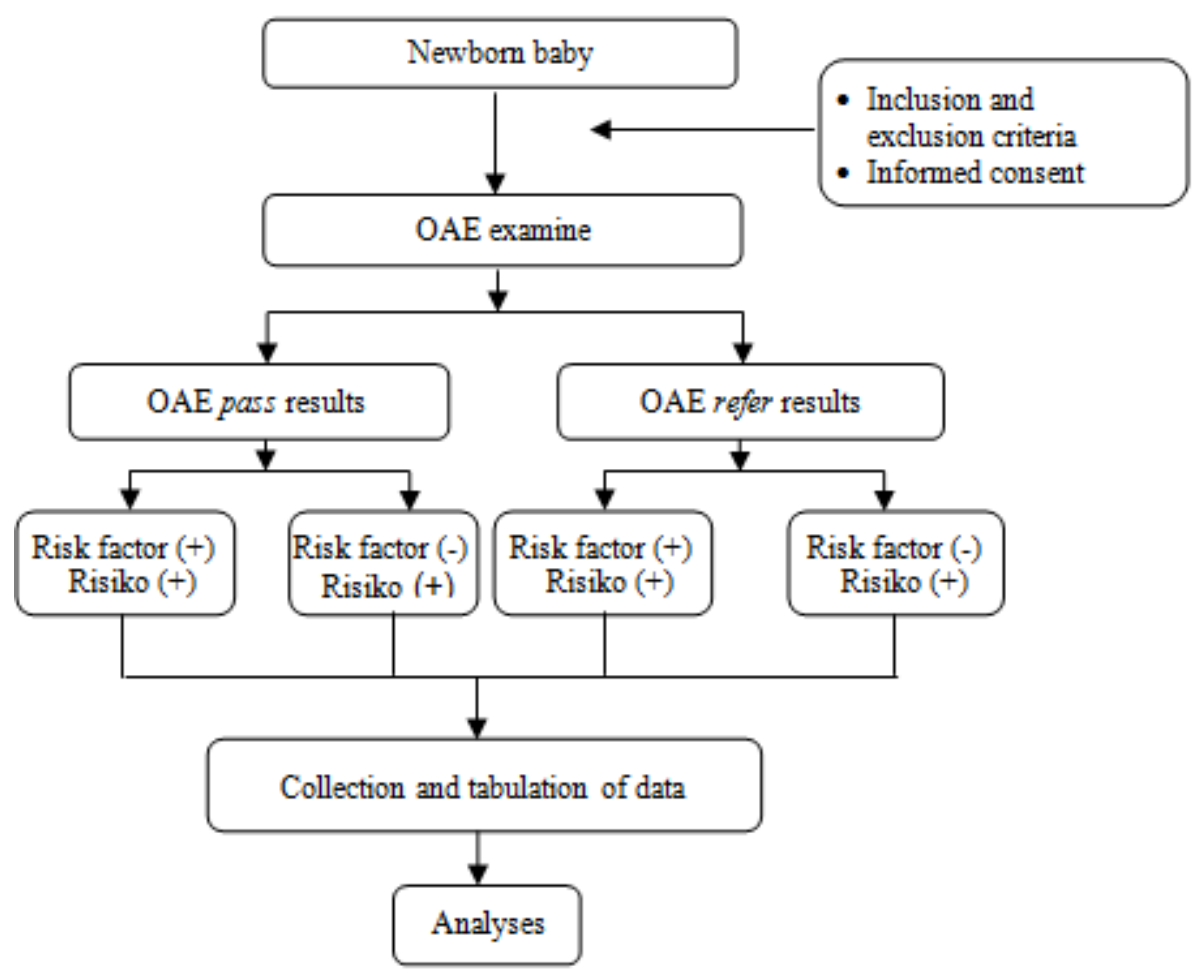

Figure 1: Study flow chart

All the data obtained are recorded in the form of research data, then each of the risk factors were analyzed with appropriate statistical methods using univariate, bivariate, and multivariate analyzes.

\section{Results}

Table 1 shows the characteristics of the samples were assessed gestational age, chronological age, sex, risk factors and function of the cochlea. The total amount of study sample was 82 subjects, which consisted of $45(54.9 \%)$ of premature infants, 57 subjects $(69.5 \%)$ who experienced 


\section{International Journal of Science and Research (IJSR) \\ ISSN (Online): 2319-7064 \\ Index Copernicus Value (2013): 6.14 | Impact Factor (2014): 5.611}

previous sepsis, $63(76.8 \%)$ subjects with a history of hyperbilirubinemia, $29(35,4 \%)$ subjects who had previously asphyxia, and 64 subjects $(78 \%)$ were treated with ototoxic antibiotics. For the category of cochlear function there were $35(42.7 \%)$ subjects with cochlear dysfunction (refer). For the category of sex found 38 $(46.3 \%)$ samples of male and $44(53.7 \%)$ samples of female. In the age group obtained a median 13 days, range 4-36 days, mean of 15.06 days and standard deviations of 7.38 days.

Table 1: Study characteristics

\begin{tabular}{|c|c|c|}
\hline No. & Sample characteristics & Total $(n=82)$ \\
\hline \multirow[t]{2}{*}{1.} & Sex & \\
\hline & Male : Female (\%) & $38: 44(46.3: 53.7)$ \\
\hline \multirow[t]{3}{*}{2.} & Age (Days) & \\
\hline & - Median (Range) & $13.00(4-36)$ \\
\hline & - Average (SB) & $15.06(7.38)$ \\
\hline 3. & Sepsis $(\%)$ & $57(69.5)$ \\
\hline \multirow[t]{4}{*}{4.} & Premature (\%) & $45(54.9)$ \\
\hline & Gestational age & \\
\hline & - Median (Range) & $35.50(28-42)$ \\
\hline & - Average (SB) & $35.74(3.58)$ \\
\hline 5. & Hyperbilirubinemia (\%) & $63(76.8)$ \\
\hline 6. & Phototherapy (\%) & $54(65.9)$ \\
\hline 7. & Bilirubin levels $>20 \mathrm{mg} / \mathrm{dL}$ & $10(12.2)$ \\
\hline 8. & Asphyxia (\%) & $29(35.4)$ \\
\hline \multirow[t]{4}{*}{9.} & Ototoxic antibiotics (\%) & $64(78)$ \\
\hline & Administration (Days) & \\
\hline & - Median (Range) & $10(5-16)$ \\
\hline & - Average (SB) & $10.19(2.29)$ \\
\hline \multicolumn{2}{|c|}{ 10. Cochlear dysfunction (\%) } & $35(42.7)$ \\
\hline
\end{tabular}

The results of Chi Square test risk factors for sepsis $(\mathrm{p}=$ $0.745)$ and antibiotics are ototoxic $(p=0.824)$, no significant on the incidence of dysfunction of the cochlea, whereas preterm infants with gestational age $\leq 32$ weeks, hyperbilirubinemia with levels $>20 \mathrm{mg} / \mathrm{dL}$ and asphyxia are risk factors with a value of $p<0.05$. After multivariate analyses obtained OR values for premature at $\leq 32$ weeks' gestation is AOR 11.45 ( $\mathrm{p}=0.004,95 \%$ CI 2.13 to 61.51 ), hyperbilirubinemia with bilirubin levels $>20 \mathrm{mg} / \mathrm{dL}$ ( $\mathrm{p}=$ 0.046 , AOR $10.28,95 \%$ CI 1.04 to 101.52 ) and asphyxia (p $=0.006$, AOR 5.03, 95\% CI 1.59 to 15.89) (table 2).

Table 2: Results of multiple logistic regression analyses of risk factors on the incidence of cochlear dysfunction

\begin{tabular}{|c|l|c|c|c|c|c|c|}
\hline No. & Variable & B & E.S & df & $p$ & AOR & $95 \%$ CI \\
\hline 1. & $\begin{array}{l}\text { GA } \leq 32 \\
\text { weeks }\end{array}$ & 2.439 & 0.857 & 1 & 0.004 & 11.45 & $2.13-61.51$ \\
\hline 2. & Asphyxia & 1.616 & 0.587 & 1 & 0.006 & 5.03 & $1.59-15.89$ \\
\hline 3. & $\begin{array}{l}\text { Bilirubin } \\
>20 \\
\mathrm{mg} / \mathrm{dL}\end{array}$ & 2.331 & 1.168 & 1 & 0.046 & 10.28 & $1.04-101.52$ \\
\hline 4. & Constanta & $\begin{array}{c}7.905 \\
-\end{array}$ & 1.805 & 1 & 0.000 & 0.00 & - \\
\hline
\end{tabular}

\section{b: Regression coefficient S.E : Error standard}

The study also calculates the probability of occurrence of cochlear dysfunction by a significant risk factor, whereby if there are three risk factors (premature, hyperbilirubinemia $>20$ ) and asphyxia, the probability of occurrence of cochlear dysfunction is $17.96 \%$ (Table 3 ).
Table 3: Probability cochlear dysfunction with existing risk factors

\begin{tabular}{|c|c|c|}
\hline No. & Existing risk factors & $\begin{array}{c}\text { Probability of cochlear } \\
\text { dysfunction }(\%)\end{array}$ \\
\hline 1. & Without risk factors & $0.03 \%$ \\
\hline 2. & Asphyxia & $0.18 \%$ \\
\hline 3. & Bilirubin $>20 \mathrm{mg} / \mathrm{dL}$ & $0.37 \%$ \\
\hline 4. & GA $\geq 32$ weeks & $0.42 \%$ \\
\hline 5. & Bilirubin $>20 \mathrm{mg} / \mathrm{dL}+$ asphyxia & $1.87 \%$ \\
\hline 6. & GA $\geq 32$ weeks + asphyxia & $2.08 \%$ \\
\hline 7. & $\begin{array}{c}\text { GA } \geq 32 \text { weeks }+ \text { Bilirubin }>20 \\
\mathrm{mg} / \mathrm{dL}\end{array}$ & $4.16 \%$ \\
\hline 8. & $\begin{array}{c}\text { GA } \geq 32 \text { weeks }+ \text { asphyxia }+ \\
\text { Bilirubin }>20 \mathrm{mg} / \mathrm{dL}\end{array}$ & $17.96 \%$ \\
\hline
\end{tabular}

\section{Discussion}

From this study, it was found that the prevalence of cochlear dysfunction in infants hospitalized in the Neonatal Intensive Care unit (NICU) was $42.7 \%$ of 82 subjects were examined. This result is similar to research done by $\mathrm{Ng}$ et al. who received $59.1 \%$ of infants admitted to the NICU experienced refer to the examination of the first OAE and Mannan et al. reported there is $40.5 \%$ were admitted to the NICU experiencing refer. ${ }^{[10,11]}$ There are two types of OAE, spontaneous OAE (SOAE) and evoked OAE (EOAE). SOAE an OAE that appears spontaneously without giving stimuli, while the new OAE EOAE which arise after the given stimuli from the outside. There are two types of EOAE namely Transient Evoked OAE (TEOAE) and Distortion Product OAE (DPOAE). $\left.{ }^{[12,}{ }^{13}\right]$ Minnesota Newborn Hearing Screening Program using OAE as a standard initial inspection, if found abnormalities then examined ABR. ${ }^{[14]}$

Sepsis is a condition most commonly found in the NICU and often adversely affects the baby and cause damage in various organs, including the hearing organ. This situation is causing hem agglutination and hypercoagulable resulting in cochlear blood flow and central nervous system decreases. This causes damage to the outer hair cells and the central nervous system that can result in disruption of auditory function. But in this study found no significant differences in cochlear dysfunction in infants with a history of sepsis compared not with $p=0.745(p>0.05)$. This is similar to the research conducted by Pourarian et al. and Santoso, that sepsis is not a risk factor for cochlear dysfunction. $\left.{ }^{15,} 16\right]$ However, these results differ from previous studies conducted by Meyer et al. revealed that infants with a history of sepsis have a risk of 2.57 (95\% CI 1.12 to 5.91 ) underwent cochlear dysfunction. ${ }^{[8]}$ The un significant sepsis as risk factors cochlear dysfunction may be caused by the development of early detection of sepsis and the development of antibiotics in the treatment of sepsis in infants so that better management of sepsis and further complications can be prevented.

The results showed that the incidence of prematurity is a risk factor cochlear dysfunction that is 5.43 times (95\% CI 2.03 to 14.54). This result is in line with the majority of studies examining risk factors for hearing loss in infants who were treated in the NICU. In Iran, suggested a significant 


\section{International Journal of Science and Research (IJSR) \\ ISSN (Online): 2319-7064 \\ Index Copernicus Value (2013): 6.14 | Impact Factor (2014): 5.611}

association between cochlear dysfunction with gestational age less than 37 weeks (preterm). ${ }^{[15]}$ Research conducted by Monica Amatuzzi et al. who did a post-mortem examination of the organ of hearing babies who had been treated in the NICU, histopathology showed that there is no outer hair cells in $27 \%$ of premature infants and $3 \%$ in term infants. ${ }^{[17]}$ Prematurity is one of the biggest reasons babies admitted to the NICU. Premature babies are born with the condition of the anatomy and function of the organ - which is not yet mature organs, including organs such as cochlear hearing. Organ of Corti involved in auditory sensory function has been formed and functioning on gestational age 30-32 weeks.

Based on the above explanation, then carried grouping gestational age, by dividing the gestational age $\leq 32$ weeks and $>32$ weeks, after it was examined, and the obtained results are very significant, with a value of crude odds ratio $(\mathrm{COR})=15.00$ with a $95 \% \mathrm{CI}(3.122$ to 72.06$)$, then performed multivariate analyses and earned value of 11.45 with $95 \%$ CI (2.13 to 61.51$)$, which means $\mathrm{UG} \leq 32$ weeks have a risk of 11.45 times compared infants with gestational age $>32$ week.

Cochlear dysfunction in preterm infants is not only because it is not a mature cochlea, but premature babies have a lot of complications that affect the function of the cochlea. Premature babies are very likely to develop sepsis and sepsis in the management of drugs used that include a class of ototoxic. In addition, premature infants also often experience hyperbilirubinemia and asphyxia at birth. Premature infants require long treatment; therefore, exposure to noise in the NICU room also aggravates the risk of occurrence of cochlear dysfunction. Therefore, babies born prematurely are particularly vulnerable to cochlear dysfunction because it has several risk factors cochlear dysfunction. The main concern due to excessive hyperbilirubinemia is the potential effect of neurotoxic, although it can also occur on the other cells injury. In addition to neurotoxic effects, hyperbiliribunemia can directly lead to the loss of outer hair cells in the cochlea that cause dysfunction of cochlea. This is a significant problem though there has been progress in neonatal care.

At the time of bilirubin levels are not based grouped, found no significant differences between groups of infants cochlear dysfunction hyperbilirubinemia compared to the un group with $\mathrm{p}=0.816(\mathrm{p}>0.05)$. Karaca et al. suggests the risk factor was not statistically significant hyperbilirubinemia in the incidence of cochlear dysfunction with $\mathrm{p}=0.06$ ( $\mathrm{p}$ $>0.05$ ) and Shahnaz pourorian et al. who argued the same thing. ${ }^{[11,18]}$ However, after the grouping levels of bilirubin are the most potentially lead to dysfunction of the cochlea, it was found that a meaningful outcome in infants with bilirubin levels $>20 \mathrm{mg} / \mathrm{dL}$, AOR 10.28 with a $95 \%$ CI (1.04 to 101.52) which means baby with bilirubin levels $>20$ $\mathrm{mg} / \mathrm{dL}$ had a 10.28 times greater risk of occurrence of cochlear dysfunction compared to infants bilirubin $\leq 20 \mathrm{mg}$ / $\mathrm{dL}$. This is in line with the research conducted by Korkmaz et al. who found cochlear dysfunction relationship with bilirubin levels $>20 \mathrm{mg} / \mathrm{dl}^{[19]}$ This could indicate that elevated levels of bilirubin higher and longer exposure can damage the cochlea $\mathrm{OHC}$ resulting dysfunction.
Asphyxia is one of the risk factor that is often associated with cochlear dysfunction. The results showed that the incidence of asphyxia is a risk factor cochlear dysfunction that is 5.75 times $(95 \%$ CI 1.92 to 17.18$)$. This result is similar to a previous study by Sarosa et al. who reported the incidence of cochlear dysfunction in infants with a history of asphyxia is 6 times greater than without asphyxia. ${ }^{[20]}$ One study in the Netherlands also reported the risk of cochlear dysfunction in infants that asphyxia was 1.7 times $(95 \% \mathrm{CI}$, 1.1 to 2.7$){ }^{[21]}$ Adequate oxygenation and perfusion is indispensable in optimizing the function of the cochlea. A state of severe hypoxia will cause damage irreversible cochlear namely the loss of outer hair cells (OHC) and edema stria vaskularis that will cause changes in the sound waves of mechanical form into electrochemical energy, and damage to the fibers of the auditory nerve that is attached to the outer hair cells (OHC) so auditory signal cannot be passed on to the brain stem.

The use of ototoxic drugs (aminoglycosides) is also thought to be a risk factor for the incidence of cochlear dysfunction. Aminoglycoside ototoxicity mechanism mediated by impaired mitochondrial protein synthesis, and the formation of oxygen free radicals. However, in this study showed statistically significant incidence of cochlear dysfunction by ototoxic drug risk factors was not significant with $\mathrm{p}=0.824$. Aminoglycoside ototoxicity associated with the duration of therapy, serum concentration, combination therapy with other ototoxic drugs, and direct exposure to the organ.

From these results, we obtain a regression model. With the regression model, it can be predicted the incidence of cochlear dysfunction; therefore, early detection of hearing loss can be done and habilitation may soon be given to support the further growth and development. In this study use the multivariate analyses with strict operational definition, so the risk factor obtained is an independent factor. However, this study also has limitations that OAE examination is not done serially; therefore further research is needed to assess the function of the cochlea. In addition to the studies did not measure the degree of noise NICU room that could also affect the incidence of cochlear dysfunction and the sample is not homogeneous due to the age of the baby during the different examination.

\section{Conclusion}

Based on the results of the study, we concluded that the risk factors of cochlear dysfunction in infants hospitalized in NICU is prematurity with gestational age $\leq 32$ weeks, bilirubin levels $>20 \mathrm{mg} / \mathrm{dL}$ and asphyxia. While the sepsis and ototoxic drugs are not associated with the incidence of cochlear dysfunction.

\section{Future Scope}

Further studies are required because a significant risk factor in this study has a small probability, so the need for further study to examine the relationship of other risks factors for cochlear dysfunction. 


\section{International Journal of Science and Research (IJSR)}

ISSN (Online): 2319-7064

Index Copernicus Value (2013): 6.14 | Impact Factor (2014): 5.611

\section{Abbreviations}

ABR-Auditory Brainstem Response; NICU-Neonatal Intensive Care Unit; OAE-Otoacoustic Emission; OHCOuter Cell Hair; LBW-Low birth weight; SOAE-Spontaneus Otoacoustic Emission; TEOAE-Transient Evoked Otoacoustic Emissions

\section{References}

[1] Rundjan L, Amir I, Suwento R, Mangunatmadja I. Neonatal Hearing Screening High Risk. Sari Pediatri. 2005; 6 (4): 149-154.

[2] Suwento R. Hearing loss in infants and children. Day seminar on the management of hearing loss and deafness; Semarang. 2007; 1-20.

[3] World Health Organization. Situation, review and update on deafness, hearing loss and intervention programmes: proposed plans of action for prevention and alleviation of hearing impairment in countries of south-east asia region. New Delhi:WHO. 2007

[4] Bashiruddin J, Soetirto I. Hearing Loss Due to Noise (NIHL) in: Textbook of Medical Sciences ENT, Sixth Edition. Faculty of Medicine, Indonesia University. Jakarta. 2009; 49-56.

[5] Joint Committee on Infant Hearing (JCIH). American Academy of Audiology, American Academy of Pediatrics: Principles and Guidelines for Early Hearing Detection and Intervention Program Pediatrics. 2007; 106 (4)

[6] Davis A, Wood S, Healy R, Webb H, Rowe S. Risk Factors for Hearing Disorders: Epidemiologic Evidence of Change over Time in the UK. J Am Acad Audiol. 1995; 6: 365-370

[7] Nasrul. Neonatal Hearing Otoacoustic Emission Inspection Based on the OAE in Makassar (Thesis). Makassar: Hasanuddin University. 2009

[8] Meyer C, Witte J, Hildmann A, Hennecke KH, Schunck $\mathrm{KU}$, Franke U, et al. Neonatal Screening for Hearing Disorder in Infants at Risk: Incidence, Risk Factors, and Follow-up. Pediatrics. 1999; 104 (4): 900-4.

[9] Smith DS. A Guide to Otoacoustic Emissions for School Nurses. 2000

[10] Mannan MA, Choudhury SM, Dey AC. et al. Newborn hearing screening: What are we missing? Bangladesh Med Res Counc Bull. 2014; 40: 1-5

[11] Pourarian S, Khademi B, Pishva N, Jamali A. Prevalence of Hearing Loss in Newborns Admitted to Neonatal Intensive Care Unit. Iranian Journal of Otorhinolaryngology. 2012; 3 (24): 129-134

[12] Campbell KCM. Otoacoustic Emissions. 2006

[13] John M, Balraj A, Kurien M. Neonatal Screening for hearing loss: pilot study from a tertiary care centre. Indian J Otolaryngol Head and Neck surg. 2009; 61: 2326

[14] Ng PK, Hui. Lam BCC, Goh WHS, Yeung CY. Feasibility of implementation universal neonatal hearing screening programme using distortion product otoacoustic emission detection at a university hospital in Hong Kong. Hong Kong Med Journal. 2004; 10: 6-13

[15] Santoso HA. Early Detection Function Disorders Cochlear Outer Hair Cell Based Transient Evoked Otoacoustic Emissions Inspection and Analysis of High
Risk Factors in Post-Baby Care in Space Intermediates IRNA Pediatrics Hospital Dr. Soetomo (Thesis). Surabaya: Airlangga University. 2009

[16] Amatuzzi M, Liberman MC, Northrop C. Selective Inner Hair Cell Loss in Prematurity: A Temporal Bone Study of Infants from a Neonatal Intensive Care Unit. Journal of the Association for Research in Otolaryngology. 2011; 12: 595-604.

[17] Karaca T, Oysu C, Toros SZ, Naiboglu B, Verim A. Is hearing Loss in Infants Associated With Risk Factors? Evaluation of the Frequency of Risk Factors. Clinical and Experimental Otorhinolaryngology. 2014; 7(4): 260-263.

[18] Korkmaz B. San I, Kar M, Iynen I. Evaluation of hearing loss in patients with neonatal unconjugated hyperbilirumia. J. Med Updates. 2013: 3 (2): 45-50

[19] Sarosa GI, Putrianti AH, Setyarini TK. Effect of Neonatal Asphyxia Against Hearing Loss. Sari Pediatri. 2011; 13 (1): 5-13

[20]Hille ET, Straaten HI, Verkerk PH. Prevalence and Independent Risk Factors for Hearing Loss in NICU infants. Acta Paediatr. 2007; 96 (8): 1155-1158 